\title{
Economía y urgencia fiscal: los asientos hacendísticos del Consulado de Lima en la segunda mitad del siglo XVII
}

ISMAEL JIMÉNEZ JIMÉNEZ

Universidad de Sevilla

ijimenez5@us.es

\section{RESUMEN}

Un panorama nada halagüeño para la economía virreinal peruana en el que los precios experimentaban alzas y la producción de riqueza se hallaba en pleno estancamiento, provocaba que los ingresos tributarios de la Monarquia se paralizasen en el mejor de los casos. Ante esta coyuntura, la mejor solución para la actividad económica y engrosar las arcas de la Real Hacienda fue entregar la percepción de los impuestos al Consulado de Comercio de Lima. Desde entonces, la década de 1660, hasta alcanzar la siguiente centuria, se viviria en Perú una negociación constante en favor de los intereses de asentador, la Corona, y asentista, los mercaderes.

Palabras clave: Perú, siglo XVII, Consulado, tributos, asientos

\section{ABSTRACT}

The unpromising state of the colonial Peruvian economy, where prices were rising and productivity was at a standstill, led to a great slowdown in the tributary income of the Monarchy. In the face of this situation, the best solution to increase economic activity and swell the coffers of the Royal Tax Office was to hand over tax collection to Lima's Consulado de Comercio. From the 1660s through the beginning of the eighteenth century, there was constant negotiation in Peru between the consigner, the Crown, and the consignees, the merchants. Keywords: Peru, XVIIth century, Consulado, tribute, asientos 
$\mathrm{D}$ urante la segunda mitad del siglo XVII, el Perú atravesó una situación financiera que puede considerarse como estancamiento. Este estado se debió, entre otros factores, al aumento de los precios de consumo, al descenso de la producción argentífera y al menor flujo comercial entre el Callao y Sevilla. Esta última causa ha aparecido tradicionalmente como un elemento indicador de la situación real de la economía del virreinato y continúa siendo válida durante el período que centra este artículo. Así, el análisis de las cuentas que los oficiales fenecían a las Cajas Reales y, principalmente, a la Caja de la ciudad de Los Reyes se antoja fundamental para comprender el momento que atravesaba la Real Hacienda. De la misma manera, los principales gestores del Erario Regio se encontraron en una situación complicada, pues su autoridad se vio progresivamente limitada, no por disposiciones de la Corona, sino por el aumento de la permisividad fiscal de la que estaban siendo beneficiadas las élites comerciales. ${ }^{1}$ A ello se sumó la necesidad de que recaudadores externos se encargaran de percibir aquellos gravámenes que el Fisco no podía tomar de forma directa. Así, de los cuarenta y dos tributos vigentes en el distrito de la Audiencia de Lima durante el siglo XVII, los contadores de la Caja limeña solo se responsabilizaron de percibir diez. Los treinta y dos restantes estaban en manos de particulares, instituciones de diversa índole y organizaciones de carácter religioso o económico que se encargaban de esta «recolección» por medio de un asiento con la Monarquía. ${ }^{2}$ En cualquier caso, el estado financiero del virreinato no debió ser muy halagüeño cuando se externalizaron aspectos tan importantes como la recaudación fiscal, por lo que nos proponemos analizar por qué se buscaron soluciones en el sector que mayores ingresos proporcionaba: el comercio.

Sobre el estado de la economía virreinal a través de la fiscalidad, puede decirse que presentó un panorama decreciente durante el reinado de Carlos II. Este escenario fue percibido desde la lejana Corte, pues de otra forma no se hubiese ordenado que los encomenderos entregasen la

1 Suárez 2001: 301.

2 Andrien 2011: 128. 
tercera parte de sus rentas. Una medida como esta refrendaba la situación ya asumida de que en el Perú los ingresos fiscales estaban descendiendo y que, por ello, se necesitaba el empleo de recursos extraordinarios, como que estos súbditos tributasen con un tercio del rédito de las encomiendas. Mediante estos ingresos, se buscó corregir el déficit de las diferentes Cajas Reales y así sanear a corto plazo los libros contables para generar las solicitadas remesas con destino a la Península. ${ }^{3}$

Podría decirse que a esta cantidad de tasas impositivas sobre los súbditos peruanos le correspondió, casi de forma pareja, la necesidad de una fuente solvente de crédito financiero para hacer frente a las demandas del Fisco. En una situación económica que — hacemos hincapié- puede considerarse de estanflación, el desarrollo del negocio prestamista se antojó fundamental; más aún cuando oferta —individuos y grupos con capacidad monetaria - y demanda - personas e instituciones con necesidad imperante de circulante- coincidieron casi desde la pacificación del Perú tras las guerras civiles que impidieron la estabilidad del territorio entre 1534 y 1554 . Además, se dio la circunstancia que entre oferente, principalmente los comerciantes, y demandante, la propia Corona, se erigió una institución intermediaria en 1613. Desde entonces, todo el flujo crediticio quedó regulado de manera oficial a través del Tribunal del Consulado de Lima. ${ }^{4}$

Así pues, establecido el Comercio de forma orgánica, la Real Hacienda del virreinato fue pasando progresivamente de usar el préstamo de hombres individuales para cubrir las previsiones de ingresos impositivos a emplear la oferta que presentaba el gremio de cargadores limeños. No obstante, la utilización de esta primera vía para paliar las necesidades hacendísticas —e incluso para aumentar las remesas con destino a la Península - siguió vigente durante todo el siglo XVII. Como consecuencia, la economía peruana estableció estrechos lazos con los intereses de determinados hombres con negocios en la jurisdicción, situación inconveniente para mantener el control sobre el mercado virreinal. Así

3 Andrien 2011: 498.

4 Rodríguez Vicente 1960: 142-143. 
ocurrió con Juan de la Cueva, afamado prestamista, quien, al quebrar en 1635, provocó una inestabilidad peligrosa en la Caja Real de Lima. ${ }^{5}$ Hasta tal punto llegó este caso que acabó por hacer que los oficiales reales se negaran a acordar futuras operaciones financieras con una sola persona y adoptaran la decisión de vincular los movimientos con varios sujetos o casas crediticias. ${ }^{6}$ Gracias a esta medida se consiguió que la administración gozase de una mayor independencia sobre los poderes de las diferentes élites locales y sus injerencias derivadas al aceptar los adelantos de tributos a cambio de intereses. Además, la nueva postura — por desgracia, no muy duradera - dotó al sistema económico de una mayor estabilidad, aunque no de la suficiente como para evitar su retroceso.

De cualquier forma, la siempre hambrienta Hacienda Real no dejó de requerir ingresos suplementarios, extraordinarios y de naturaleza diferente al crédito. Aunque Carlos II no echó mano de recursos tan eufemísticos en su denominación como los donativos, empréstitos o repartimientos al mismo nivel que lo había hecho su padre, sí solicitó en Perú, por medio del Consejo de Hacienda y el Consejo de Indias, la colaboración monetaria para hacer frente a diferentes contingencias que se le presentaron a la Monarquía católica. ${ }^{7}$ Estas solicitudes, con un carácter más forzoso que voluntario, estuvieron siempre enmarcadas en las necesidades pecuniarias originadas por las guerras y, más aún, en las postrimerías del siglo XVII, pues se combinaron la preparación del tablero para la sucesión del trono Habsburgo con un teatro de operaciones doble para los futuros conflictos: el europeo y el peninsular.

Con todo ello, sin olvidar el contexto de estancamiento y aumento de los precios, el virreinato peruano y, principalmente, la ciudad de Los Reyes hubieron de realizar sucesivos esfuerzos para cumplir con estos donativos. El primero de ellos tuvo lugar en 1663, cuando desde la Corte se solicitó una ayuda importante, a satisfacer en pesos de a ocho, con motivos aparentemente bélicos. Aunque Manuel de Mendiburu dice

5 Suárez 2001: 77-98.

6 Andrien 2011: 88.

7 Domínguez Ortiz 1960: 309. 
que este dinero iba a ser destinado a la guerra contra Francia, ${ }^{8}$ el destino de la plata no fue exactamente este. Ese año, las relaciones entre ambas potencias se hallaban en calma tras la firma de la Paz de los Pirineos el 7 de noviembre de 1659. El esfuerzo pedido a los limeños tuvo como finalidad sufragar los gastos generados por la última campańa, preparada desde Madrid, para recuperar Portugal. Estas operaciones acabaron con la derrota definitiva para las armas castellanas en la batalla de Villaviciosa el 17 de junio de 1665 .

También se solicitaron caudales en ocasiones posteriores y con finalidades diversas, como los casamientos del rey con María Luisa de Orleans en 1679 y con Mariana de Neoburgo en 1690. La misma petición se hizo con motivos más útiles a la Corona, sin obviar la importancia que los matrimonios supusieron en el entramado diplomático de la política europea de los siglos modernos. Así, por ejemplo, cuando los comerciantes se negaban a embarcar sus mercaderías en la Armada del Mar del Sur en la fecha fijada, esgrimiendo como excusas el no haber recibido aviso en fecha conveniente desde Panamá o en la escasa seguridad coyuntural del Pacífico, los galeones de Tierra Firme originaban unos sobrecostes que trastocaban las delicadísimas cuentas presupuestadas por la Corona. En situaciones como estas, se solicitaron empréstitos para cuadrar los balances y satisfacer las deudas creadas por las demoras. De la misma forma, cuando ciertos virreyes quisieron aumentar su "fama» ante la Corte por medio de la remisión de remesas metálicas importantes, también acudieron a estos donativos — fundamentalmente realizados por cargadores - para acrecentar el envío. Esta práctica resultó beneficiosa en lo personal, pero negativa para la administración, pues se realizaba a costa de hipotecar a la Real Hacienda con unos intereses futuros. ${ }^{9}$ Es decir, el donativo vino a incidir en esta caída de la economía peruana y, por tanto, a reducir los ingresos del Fisco generados por la propia actividad financiera.

Esta cuestión era de importancia, ya que, en el virreinato, junto con el estancamiento económico, venía observándose una merma significativa

8 Véase la sección dedicada al conde de Santisteban en Mendiburu 1874-1890, II.

9 Caracuel Moyano 1966: 338. 
en la cantidad de plata, en barras y acuñada, que se enviaba a Sevilla. Durante el siglo XVII, las Indias habían ido convirtiéndose progresivamente en un territorio autosuficiente y, en la segunda mitad de la centuria, un porcentaje mayoritario de la plata acuñada en la Casa de la Moneda de Potosí, o en la reabierta en 1683 de Lima, fue absorbida por el propio Perú para su funcionamiento cotidiano. ${ }^{10}$ A esta merma de las remesas hay que añadirle otra causa. En la segunda parte del XVII, el descenso de la rentabilidad de las empresas mineras, fruto del aumento de costos y del menor rendimiento de las vetas argentíferas, se tradujo en un crecimiento del circulante en suelo peruano. Si bien esta situación provocó la bajada del valor adquisitivo del peso de a ocho reales en un contexto saturado de monetario y, por tanto, en el ascenso de la inflación, para Kenneth Andrien, el hecho de enviarse menos remesas a España «sirvió para la creación en América de una economía mejor equilibrada y más diversificada». ${ }^{11}$

En ese sentido, la economía interna peruana tuvo un buen reflejo en la curva descrita por la acuñación de numerario. Las cecas no dejaron de sacar a circulación pesos de a ocho reales y otros tipos monetarios. Una producción como esta buscaba satisfacer al demandante mercado interno, como indican las cifras de estas fábricas. Así, para la primera mitad del siglo XVII, la Casa de la Moneda de Potosí y la interrumpida de Lima acuñaron entre 1 y 5 millones de pesos de a ocho; mientras que, para los cincuenta ańos finales de la centuria, aunando las cecas potosina y limeña se alcanzaron a poner en circulación entre 2 y 9 millones de pesos de a ocho. ${ }^{12}$ Sin embargo, la idea de una autarquía americana dentro de la Monarquía católica debe apoyarse también en la lentitud que se hizo característica en todos dominios hispánicos, no solo en la dilatación de los viajes de la Carrera de Indias. ${ }^{13}$ De la misma forma que en Perú, en todo el continente debieron tomarse iniciativas propias para solucionar problemas locales y acomodar las diferentes disposiciones legales a la

\footnotetext{
${ }^{10}$ Suárez 1995: 23.

${ }^{11}$ Andrien 2011: 51.

${ }^{12}$ Suárez 1995: 24.

${ }^{13}$ Serrera Contreras 1998: 695.
} 
realidad americana, también hubo de realizarse operaciones de adaptación en el ámbito económico. Estos movimientos buscaron principalmente el mantenimiento de los sistemas "clásicos» y, sobre todo, la salida de la estanflación que tanto afectó al virreinato en el siglo XVII.

Una de las consecuencias más importantes de la situación expuesta fue la entrega de determinados asientos fiscales al gremio de mercaderes, precisamente el grupo que más cantidad demandó a las citadas cecas peruanas. Estos asientos, auténticos contratos entre el virreinato y el Consulado de Lima para recaudar impuestos, no dejaron de crecer a lo largo de toda la centuria. Así, se revalorizaron sustancialmente, en especial aquellos que tenían como ramo la alcabala y el almojarifazgo, mostrando que el comercio pacífico, que tan de capa caída intentaba aparecer, aún originaba atractivos dividendos. En cualquier caso, la entrega de la gestión de estos tributos al — de por sí poderoso- Tribunal de mercaderes de la ciudad de Los Reyes convirtió a sus miembros en la clave de todo un sistema de economía-mundo. Desde entonces, pasaron a controlar la maquinaria comercial entre el Callao y Sevilla, la presión tributaria sobre las diferentes empresas productivas que se desarrollaban en el Perú y, en última instancia, la dirección de las «subvencionadas» explotaciones mineras. ${ }^{14}$ Por todo ello y ante la supresión de la avería dictada por el Consejo de Indias en 1660, desde el palacio virreinal limeño no quedó otra alternativa para mantener cierta estabilidad en los ingresos hacendísticos que entregar la percepción, mediante asientos, de una serie de impuestos a los comerciantes.

\section{REUNIONES, ACUERDOS Y AVENENCIAS ENTRE EL VIRREINATO Y EL}

\section{Consulado}

El doctor Lohmann Villena calificó como uno de «los mayores servicios que prestó a la Monarquía» la negociación que el conde de Santisteban del Puerto realizó con los mercaderes limeños para el ajuste de los referidos asientos. A grandes rasgos, este virrey (1661-1666) arregló con el Consulado la entrega de 350.000 ducados, correspondientes al impuesto

${ }^{14}$ Oliva Melgar 1996: 325. 
comercial de la avería, y otras cantidades bajo el concepto de almojarifazgo, alcabala y unión de armas. ${ }^{15}$ Santisteban había llegado al Perú con la tarea de alcanzar este acuerdo hacendístico con los mercaderes y tenía un buen ejemplo en los asientos que años atrás ya se habían tomado: entre 1619 y 1640 , el Consulado administró las alcabalas y, en tres etapas diferentes de la primera mitad del siglo XVII, hizo lo propio con el almojarifazgo. ${ }^{16}$ Así, apenas se hubo instalado en la ciudad de Los Reyes, el virrey comenzó a trabajar para conseguir alcanzar un acuerdo con el gremio y convencerlos de que se encargasen del arrendamiento de la avería.

Este importante impuesto corría en 1660 en manos de la Casa de la Contratación de Sevilla, alcanzando, en puntuales armadas, hasta un $6 \%$ sobre los caudales y frutos embarcados, aunque lo usual fue que variase en razón al número de navíos que componían cada convoy y a la mercancía transportada. Por este motivo, por su cambiante cuantía y por lo difícil de la articulación de establecimientos para su percepción, los fraudes aumentaron de manera proporcional a como lo hacía el propio impuesto, un escenario que ocasionó el enojo de aquellos comerciantes que sí cumplían con ellos. Así fue como el Consejo de Indias ordenó que el virrey se entendiese con el Consulado para alcanzar un concierto, fruto del cual unos y otros habrían de obtener mayores beneficios que aquellos percibidos con el sistema que se estaba empleando.

Este fue el contexto en el que Santisteban hubo de desenvolverse tras realizar su entrada en la capital peruana el 31 de julio de 1661. Sus actuaciones al respecto no se hicieron esperar y, a tenor de lo comunicado a la metrópoli, pareció que avanzaba con celeridad para cumplir lo ordenado desde la Corte. A finales de ese mismo año, el virrey redactó una carta con destino a Madrid en la que informaba tener un principio de acuerdo con el Consulado. Los cargadores iban a quedarse en arrendamiento con el impuesto del almojarifazgo durante tres años, a razón de 58.000 pesos

${ }^{15}$ Lohmann Villena 1946: 62-63.

16 Suárez 2001: 302. 
de a ocho reales en cada uno de ellos. ${ }^{17}$ Sin embargo, la principal de las tareas, que era el negocio de la avería, por el monto que suponía y por el peso tan importante que alcanzaba en el global de los presupuestos anuales de la Corona, aún estaba sin cerrarse.

Según dijo el propio virrey, los contactos con el Comercio comenzaron en los primeros meses del año de 1662 y, para mediados de febrero, ya se habían celebrado las primeras reuniones. El alter ego expuso ante los cargadores la conveniencia de que se hicieran cargo de ayudar a la Armada del Mar del Norte mediante la toma de la avería de dicho espacio, la cual representaba unos 350.000 ducados, y que si aceptaban tendrían como compensación extraeconómica ciertas consideraciones por parte de la Corona. Por ello comunicó al rey el inicio de las negociaciones y, a su vez, dejándolo caer entre líneas, solicitaba que, en caso de conseguir la aprobación de los asientos por parte del Tribunal, se les premiase con "afectos», como hábitos de las órdenes militares. ${ }^{18}$

Las entrevistas entre los comerciantes y el propio virrey fueron farragosas, ya que en ningún documento se hace referencia a que durante estas reuniones Santisteban estuviese representado por algún procurador o por algún miembro de la Audiencia de Lima o del Tribunal de Cuentas. El vicesoberano tenía el encargo personal y así quiso llevarlo a cabo. No obstante, a pesar de su presencia, si una característica tuvieron los asientos de la avería fue la de ser negociados con una lentitud terrible para los intereses metropolitanos, pues era la parte con la necesidad de asegurarse una renta anual más o menos estable. Así, pasaron ocho meses desde que comenzaron en febrero a sentarse ambas partes hasta alcanzar un principio de acuerdo. Para entonces, el virrey volvió a remitir noticias a España en las que hablaba de un primer trato con el Consulado, aceptando el hacerse cargo de la percepción de la avería del Mar del Sur durante las próximas cuatro «ocasiones de armada». A cambio, los

${ }^{17}$ Carta del conde de Santisteban al Rey. Lima, 27 de diciembre de 1661. Archivo General de Indias [en adelante AGI], Lima, 63.

${ }^{18}$ Carta del conde de Santisteban al Rey. Lima, 17 de febrero de 1662. AGI, Lima, 63. 
mercaderes se comprometieron a ingresar cada vez en la Caja Real de Lima 80.000 pesos de a ocho reales. ${ }^{19}$

En las reuniones no solo se tocaron temas pertenecientes al impuesto mercantil meridional, sino que, según informa Santisteban, la tasa septentrional también fue objeto de discusiones durante prácticamente todo el año de 1662. A la postre, también se alcanzó un acuerdo sobre esta última —en este caso se informaba con un día de retraso- - No cabe duda de que ambos gravámenes se acordaron de una vez, aunque el Consulado poseyese potestad únicamente en el Pacífico. De esta forma, el virrey trasladó al Consejo de Indias el acuerdo por el que el Comercio de Lima se encargaba de satisfacer 350.000 ducados durante cuatro armadas. ${ }^{20}$ Ajustadas estas cantidades, el vicesoberano pudo decir con rotundidad que había cumplido con uno de los cometidos que con mayor urgencia se le asignaron desde la Corte y, además, en las cantidades exactas que el Consejo le había estipulado. Esto constituyó todo un mérito para el timorato militar que fue don Diego de Benavides, pues no es difícil imaginar la ferocidad con la que seguramente se desempeñaron los comerciantes peruanos en las negociaciones.

Los acuerdos entre el virrey y el Consulado se llevaron a documento oficial de seguido. En el Callao, el escribano mayor de la Real Hacienda, Fernando Dávila, elevó escritura por la que se comprometían a cumplir lo tratado durante las próximas cuatro armadas. ${ }^{21}$ Sin embargo, lo que parecía el final de un largo tira y afloja no fue más que eso, una apariencia. Tras haber sido rubricados los acuerdos, el Comercio volvió tras sus huellas y comunicó al virrey que no iban a ejecutar nada de lo concerniente a la avería del Norte hasta que sus representantes delegados en la Corte acabasen las gestiones que tenían designadas; es decir, la averiguación de que el asiento se ajustaba a la legislación real. Ante ello, Santisteban puso en conocimiento a la Corona del paso atrás dado por los cargadores, aprovechando, como medida de presión, para hacer saber

${ }^{19}$ Carta del conde de Santisteban al Rey. Lima, 22 de noviembre de 1662. AGI, Lima, 63.

${ }^{20}$ Carta del conde de Santisteban al Rey. Lima, 23 de noviembre de 1662. AGI, Lima, 63.

${ }^{21}$ Escritura del asiento con el Consulado realizada por Fernando Dávila. Callao, 29 de noviembre de 1662. AGI, Lima, 63. 
que los oficiales reales encargados de la inspección de los buques entre el Callao y Panamá habían encontrado cierta cantidad oculta de lingotes de plata en las embarcaciones comerciales. ${ }^{22}$

Los asientos establecidos se encontraron en una coyuntura delicada: ni los mercaderes podían recaudar los impuestos comerciales y ni las arcas virreinales podían recibir un solo peso en concepto de avería. La situación se hallaba congelada, pero resultaba ser que, durante 1663 y 1664, este no era el único de los arrendamientos paralizados. Debido a que la demanda de esclavos estaba superando la escasa oferta, originando protestas dirigidas a la sede virreinal, Santisteban tuvo que pedir que se cumpliese de inmediato el asiento de negros, asignado desde 1663 a la compañía formada por Domingo Grillo y Ambrosio Lomelín. ${ }^{23}$

El escenario no era el más agradable para la administración peruana y, ante las necesidades urgentes de la Monarquía en Europa, alguna solución habría de ingeniarse. Los ingresos en la Caja Real de Lima estaban sufriendo una mengua importante al aunarse el descenso de la producción minera - y, por tanto, del quinto real — con el impago de los tributos comerciales causado por la negativa a cumplir con los asientos por parte del Consulado. En ese contexto, zarparon desde Sevilla los galeones de Tierra Firme que se esperaban en Portobello a finales de 1664 para la celebración de la feria y la carga de las remesas con destino a España. Así, teniendo noticia de la llegada del convoy al istmo, al virrey no le quedó otra que reunirse con la Junta de Hacienda del Perú para buscar una forma inmediata de incrementar el envío destinado al rey. Esta conferencia tuvo lugar el 16 de julio y fruto de ella fue el acuerdo de remitir a España un millón de pesos de a ocho reales. ${ }^{24}$ Sin embargo, debido a los escasos ingresos de la Hacienda Real, este incremento se realizó mediante el uso de caudales de prestamistas, la mayoría vinculados al Comercio, que a cambio de un bajo interés colaboraron con las necesidades de la

${ }^{22}$ Carta del conde de Santisteban al Rey. Lima, 26 de diciembre de 1662. AGI, Lima, 63.

${ }^{23}$ Carta del conde de Santisteban a Francisco Ramos del Manzano, presidente del Consejo de Indias. Lima, 20 de octubre de 1664. AGI, Lima, 66.

${ }^{24}$ Carta del conde de Santisteban al Rey. Lima, 24 de noviembre de 1664. AGI, Lima, 66. 
Corona. ${ }^{25}$ Así fue como partieron los navíos de la Armada del Mar del Sur desde el Callao el 8 de diciembre de 1664, gestionados directamente por el mismísimo alter ego, con una plata prestada y con una avería sin satisfacer por haberse negado los comerciantes a encargarse de su percepción. ${ }^{26}$ Desde luego era una situación que urgía de una solución inmediata, pues la maquinaria del Erario no podía permanecer más tiempo pausada. Las necesidades, cada mes que pasaba, apremiaban a lograr un arreglo y devolver a la normalidad el sistema fiscal peruano.

No fue sino hasta finales de 1666 que en el Consejo de Indias se tuvieron las primeras noticias de que los asientos acordados entre el difunto conde de Santisteban y el Tribunal del Consulado de Lima se habían llevado a efecto. Sin embargo, dado que para 1665 no se tenían noticias de cobros, podría decirse que se mantuvo en suspenso este contrato impositivo. La realidad difiere del supuesto, pues, durante ese año, el virrey no paró de reunirse con los mercaderes hasta alcanzar, en común acuerdo con los oficiales reales, un consenso por el que resolver y poner en marcha el asiento para la avería, el almojarifazgo, la alcabala y la unión de armas. Así, no cayeron los esfuerzos virreinales en saco roto, ya que el día de Navidad de 1665 se dató un memorial dirigido a la Corte en que se dio buena cuenta del nuevo mecanismo por el que se nutriría el Fisco virreinal. ${ }^{27}$

De esta forma, para noviembre de 1666, el capitán Juan de Urdanegui, nombrado por el Comercio como administrador general de los almojarifazgos, certificó la entrega de 113.000 pesos de a ocho reales a la Caja Real de Lima, a pesar de que no eran más que las cantidades de la anualidad según lo dispuesto en 1664. Además de ello, el gestor hace saber en la Corte que se habían obtenido unos 40.000 pesos por encima de lo estipulado, pero que este monto iba a ser retenido por los cargadores como medio para sufragar las estructuras de cobro que necesitaban. Sin embargo, también cita unos 60.000 pesos extraordinarios que fueron tomados por los asentistas y que se depositarían en favor de

${ }^{25}$ Autos de la Junta de Hacienda del 16 de julio de 1664. Callao, 26 de noviembre de 1664. AGI, Lima, 66.

${ }^{26}$ Carta del conde de Santisteban al Rey. Callao, 8 de diciembre de 1664. AGI, Lima, 66.

${ }^{27}$ Hanke y Rodríguez 1979, IV: 183. 
la Real Hacienda en el plazo de las próximas cuatro armadas, tal como estaba dispuesto en los acuerdos. ${ }^{28}$

Esta información indicaba que el asiento no solo había comenzado a funcionar sino que, además, presentaba visos de mantener una continuidad en un plazo superior al acordado con la Corona. Así parecía, pues el conde de Lemos no remitió noticias a Espańa al respecto sino hasta dos años después de su toma de posesión como virrey del Perú. Para entonces, en 1669, lo que hizo el vicesoberano fue poner en conocimiento del Consejo que, a su llegada en 1667, el Comercio debía a la Real Hacienda por los conceptos de almojarifazgo y unión de armas un total de 94.573 pesos y 6 reales, pero que, gracias a su gestión personal, la deuda estaba casi liquidada. La medida adoptada por Lemos para este cobro no fue otra que la de hacer que el gremio nombrase como prior del Consulado a Juan de Urdanegui, quien, como se ha indicado más arriba, era el encargado de recaudar los gravámenes acordados. ${ }^{29}$

Desde entonces, el arrendamiento entre cargadores y el virreinato corrió prácticamente sin sobresaltos, llegando a superar las cuatro armadas convenidas a priori. Sin embargo, la llegada del «economista» virrey conde del Castellar modificó el status quo mantenido desde 1664 y 1666. Este virrey había recibido en Lima una real cédula fechada el 16 de noviembre de 1676 en la que se le ordenaba que incrementase el impuesto de la avería en un cincuenta por cierto; es decir, que pasara esta tasa del $2 \%$ ad valorem de lo fletado en las armadas a un 3\%. La respuesta del Consulado no sorprendió en demasía, pues se negaron a la subida que desde la metrópoli se justificaba en la necesidad de botar nuevos buques para la Armada del Mar del Sur. En respuesta a este rechazo, y apoyándose en que los mercaderes debían 300.000 pesos de a ocho reales pertenecientes a la avería del Norte, Castellar optó por comunicar a la Corte la inviabilidad de este aumento en la presión fiscal y suspender los asientos «hasta mayor coyuntura». ${ }^{30}$

${ }^{28}$ Memorial del capitán Juan de Urdanegui al Rey. Lima, 24 de noviembre de 1666. AGI, Lima, 66.

${ }^{29}$ Carta del conde de Lemos al Rey. Lima, 16 de marzo de 1669. AGI, Lima, 68.

${ }^{30}$ Hanke y Rodríguez 1979, V: 75. 
El Comercio no solo tuvo este motivo para enemistarse con el virrey. Castellar, además de suspender de forma cautelar los asientos, había dispuesto la apertura del tráfico comercial entre los virreinatos de Perú y México, originando un incremento de la oferta de bienes asiáticos importados a los mercados andinos por la vía de Acapulco. El Consulado rápidamente respondió a esta medida indicando, a través de memoriales dirigidos a la Corte, que precisamente por la legalización de este nuevo eje mercantil la feria de Portobello, aquella en la que más cantidad de mercaderías se traspasaban y de la que mayores beneficios obtenían, había decaído enormemente. Así pues, todo ello provocaba su incapacidad para satisfacer la deuda de la avería del Norte por los citados 300.000 pesos. Las protestas tuvieron calado en Madrid y fueron uno más de los detonantes que llevaron al rey a retirar de Lima a Castellar mediante la real cédula del 7 de julio de $1678 .^{31}$

De aquí nacieron nuevas presiones por parte de los comerciantes para cancelar los asientos, que ya se estaban prolongando más de lo conveniente a los intereses de su gremio. En este sentido, cuatro años después de la deposición de Castellar, el prior y los cónsules de ese año, Alonso Ximénez Vela de Lara, Francisco de Oyagüe y Roque de Segura Aguado respectivamente, decidieron hacer saber en Madrid que el Consulado se encontraba en una situación financiera límite, pues el contrato de arrendamiento de la avería y la paralización de las transacciones marítimas, por la presencia casi continuada de filibusteros en el Pacífico, habían logrado hacer que la actividad - los ingresos - del Comercio quedase muy comprometida. Esto explicó el hecho de que, en las elecciones gremiales de 1682, nadie quisiera presentar candidatura a ocupar los cargos de responsabilidad, por lo que el prior Ximénez y el cónsul Segura hubieron de aceptar sendas prórrogas tras las presiones sometidas por el virrey duque de la Palata. ${ }^{32}$ No cabe duda de esta situación económica, pero, teniendo en cuenta la situación precedente de las relaciones

\footnotetext{
${ }^{31}$ Andrien 2011: 235.

${ }^{32}$ Carta del prior y los cónsules del Comercio al Rey. Lima, 25 de enero de 1682. AGI, Lima, 107.
} 
entre el Consulado y el virreinato y observando que los asientos ya no resultaban tan rentables, también debería considerarse la posibilidad de que lo buscado por los comerciantes fuera el librarse del «lastre» de los acuerdos fiscales.

A finales de 1682, los miembros del Comercio volvieron a escribir a la Corona solicitando la cancelación de los asientos. Los diputados comentaban que, al observar que las rentas reales del Perú no hacían más que descender, ellos no podían alcanzar a recaudar lo estipulado en los asientos para cada armada y que, por esta razón, tenían que acudir al mercado crediticio para engrosar los tributos hasta el límite acordado. El paisaje descrito por los mercaderes resultaba tremendamente perjudicial para sus propios intereses. Así, solicitaron al rey «se sirva de admitirle la dejación» de los asientos a cambio de un donativo "gracioso" de 100.000 pesos de a ocho reales, a depositar en la Caja Real de Lima en un solo plazo. Sin embargo, para «regalar» tal cantidad de dinero a cambio de cancelar los asientos, los comerciantes pusieron dos condiciones: la primera, que se disuelvan los arrendamientos antes de que la próxima armada haga su aparición en Portobello, pues entonces ya estarían obligados a satisfacer los impuestos de esa ocasión; y, la segunda, que se le conceda al Consulado un poder especial para repartir y cobrar en depósito las averías prorrateadas hasta la cantidad de 100.000 pesos. $^{33}$ En definitiva, de una u otra forma los cargadores saldrían beneficiados, puesto que si conservaban los asientos, en una coyuntura ventajosa, obtendrían pingües beneficios o, en un contexto menos rentable como el de los años precedentes a 1682, podrían cancelar sus obligaciones por medio de un obsequio en metálico.

Año y medio después de esta solicitud del Consulado, el Consejo de Indias se reunió para analizar la dejación de los asientos de averías, alcabalas, almojarifazgo y unión de armas, a pesar de que aún quedaban dos armadas para que se diesen por finalizados estos acuerdos. Los consejeros no vieron con buenos ojos la petición que desde Lima les llegaba y así se

${ }^{33}$ Carta de los diputados del Comercio al Rey. Lima, 24 de diciembre de 1682. AGI, Lima, 107. 
lo hicieron saber a Carlos II. Ante el Monarca presentaron una serie de inconvenientes por los que denegar la petición, a pesar del donativo ofrecido, como fueron: que no se atenía a justicia la dejación de los asientos; que, aunque elevado hasta el 7\% el tributo de la avería, por la gestión del Consulado rentaba más; que su cobro era más factible en manos de los mercaderes, dadas las dificultades que tenía la Real Hacienda para la recaudación, en parte por los fraudes cometidos por los propios cargadores; que interpretan en el Consejo que el Comercio intentaba cancelar los asientos para negociar unos nuevos, con mayores ventajas para sí y menores rentas para el rey; y que, a pesar de que decían no poder satisfacer las cantidades acordadas, en ningún caso se desprendieron de los derechos sobre estos gravámenes, aunque los estaban solicitando como subarrendatarios "ciertos vecinos» de la ciudad de Panamá y un tal Juan de Montenegro. ${ }^{34}$ Como puede verse, la distancia que separaba los centros de poder - Lima y Madrid - no fue decisiva para que en la Corte se tomasen por ciertas todas las informaciones llegadas del virreinato. En el Consejo vieron, casi desde la recepción de las cartas y memoriales del Comercio, que algo se ocultaba entre líneas. Además, no se podía permitir que rentas aseguradas, como las de estos asientos, se perdiesen casi de la noche a la mańana.

De esta manera, poco después de negársele al Tribunal la cancelación de los contratos, mediante real cédula se le recordó al virrey Palata las emitidas el 30 de noviembre de 1664 y el 20 de mayo de 1666 que establecían los asientos acordados por ambas partes y que aún no se habían agotado. Además, se conmina al vicesoberano a negociar la prórroga de los contratos que querían cancelarse y a corregir por todos los medios el abuso que venía dándose en los mismos, pues se comprobó que los delegados del Consulado habían percibido cantidades superiores a las que anualmente debían satisfacer. ${ }^{35}$ El 1 de septiembre de 1684, la Corona mandó al Perú la respuesta definitiva a las peticiones del Comercio: negaba la suspensión de los asientos, pero aceptaba gustosamente el

${ }^{34}$ Consulta del Consejo de Indias al Rey. Madrid, 25 de agosto de 1684. AGI, Lima, 281.

${ }^{35}$ Real Cédula del Rey al duque de la Palata. Madrid, 27 de agosto de 1684. AGI, Lima, 281. 
donativo de 100.000 pesos de a ocho reales. Conocida la decisión por los cargadores peruanos, no les quedó otra que responder a la Corte dando a Carlos II las gracias - muy cargadas de ironía - por haber desoído sus peticiones, pero sí aceptar el regalo ofrecido en satisfacción de sus demandas. ${ }^{36}$

¿Continuaban vigentes los asientos en este momento (1648)? ¿Había cambiado la coyuntura mercantil en el Pacífico? A ambas interrogantes se responde con una negativa. Así, tras recibir la orden de enterar en la Caja Real de Lima los 100.000 pesos por la «cancelación» de los asientos, los cargadores encontraron varios problemas. Por un lado, no disponían de esta suma y, por otro, el riesgo de quiebra que suponía el desembolso era considerable. Estos, sin embargo, no fueron atenuantes suficientes para evitar el cumplimiento del donativo. ${ }^{37}$ El peligro de que la estructura gremial colapsase pareció importar poco dentro de la Monarquía y del propio Perú, pues de otra forma no podría explicarse que se presionase tanto a los comerciantes. Además, el virrey Palata forzó un poco más al Consulado remitiendo a la Corte un balance negativo sobre su gestión institucional. A la fecha de su memorial, a fines de mayo de 1685, el Comercio acumulaba, solo desde 1682, deudas por valor de 284.434 pesos en concepto de la administración de averías, alcabala, almojarifazgo y unión de armas. ${ }^{38} \mathrm{El}$ hecho de que los comerciantes se dirigiesen al virrey para expresar su mala situación y lo inconveniente de entregar el donativo, sumado al informe de deudas enviados por Palata a la metrópoli, reveló cierta enemistad entre Palata y los cargadores de Lima. Sin embargo, el riesgo de quiebra era asumible, pues se trataba de todo un órdago del Tribunal para deshacerse de las obligaciones acordadas.

En cualquier caso, durante los primeros meses de 1687 Palata volvió a mostrarse contrario a la donación de 100.000 pesos del Comercio como contraprestación a la cancelación de los asientos. El Consulado no dejaba de insistir en que enterado este dinero en la Caja Real limeña deberían

${ }^{36}$ Carta de los diputados del Comercio al Rey. Callao, 20 de abril de 1685. AGI, Lima, 281.

${ }^{37}$ Carta del prior y cónsules del Comercio a Palata. S. 1., 1685. AGI, Lima, 281.

${ }^{38}$ Memorial del duque de la Palata al Rey. Lima, 28 de mayo de 1685. AGI, Lima, 281. 
quedar automáticamente exonerados de sus deberes arrendatarios, pero Palata se negó apoyándose en tres estrategias. La primera de ellas consistió en una propuesta: si el Tribunal deseaba romper los contratos, los cargadores debían registrar en el Callao las mercancías con destino a Panamá cada dos años por valor de diez millones de pesos o bien cada tres por un total de quince. Los comerciantes respondieron negativamente. La segunda opción fue disminuir el número de miembros del Comercio que debían acudir a las ferias de Portobello, pues se observó que, al ser más de 600 los asistentes, las pugnas entre ellos por adquirir los géneros elevaban los precios. La tercera y última estrategia que el alter ego expuso para no cancelar los asientos fue el negar la presumida decadencia de la actividad mercantil. En este sentido, Palata sentenció: «yo no he visto seña por donde se pueda conocer que está descaecido el comercio». ${ }^{39}$

Probablemente, las desavenencias entre Palata y los comerciantes fueron azuzadas tras la orden recibida por el primero desde la Corte con fecha de 4 de septiembre de 1683. En ella se ordenó al vicesoberano renegociar de alguna forma los asientos con el Consulado. Pero, según se vio, sus esfuerzos para lograrlo no fueron fructíferos. $\mathrm{Al}$ no conseguir un acuerdo que satisficiese los intereses de la Corona en el Perú — lo cual hubiese reforzado la importancia y el papel de Palata como virrey- aumentó el descontento entre los mercaderes y la sede virreinal. Esta misma orden fue repetida al nuevo alter ego, el conde de la Monclova, el 3 de marzo de 1688 , como acompañamiento de las instrucciones que se le remitieron a México. El nuevo virrey, al arribar a Lima, observó que alcanzar un acuerdo de renovación sería una tarea difícil. Para empezar, había que sentarse en la mesa con los cargadores de forma menos agresiva que la adoptada por Palata, lo cual no sería sencillo porque, para proteger sus intereses, los comerciantes continuaban negociando de manera combativa. ${ }^{40}$

Entre un virrey y otro no solo había cambiado la forma de abordar la cuestión de los asientos sino que, además, un acontecimiento obligó a

\footnotetext{
${ }^{39}$ García Fuentes 1979: 267.

${ }^{40}$ Carta del conde de la Monclova al Rey sobre la negociación de los asientos con el Consulado. Lima, 20 de junio de 1690. AGI, Lima, 427.
} 
replantear todo: el terremoto del 20 de octubre de 1687. Tras el sismo, con la destrucción del Callao y buena parte de Lima, se hizo necesaria la supresión de determinados gravámenes para acelerar e incentivar las tareas de reconstrucción. Sin embargo, de la dispensa tributaria concedida por Carlos II solo se excluyeron tres: el impuesto sobre el papel sellado, los destinados a la Armada del Mar del Sur y la avería. Esta situación, además de la mayor benevolencia de Monclova en las negociaciones, llevó al Consulado a solicitar la supresión inmediata de los asientos, pero también a cancelar «el que se disponía» para acordase en los meses inmediatos. ${ }^{41}$

La presión ejercida por el Tribunal no fue óbice para que se continuase la tarea encomendada a Palata: acordar unos nuevos asientos. A pesar de que los cargadores habían solicitado la dicha supresión, el virrey consiguió sentarlos en torno a una mesa para alcanzar un acuerdo. Esta primera reunión tuvo lugar el 6 de octubre de 1689. Para ello, Monclova les había hecho saber a los comerciantes que estaban obligados por la Monarquía a alcanzar un entente rentable tanto para la Real Hacienda como para los cargadores. La respuesta del Consulado al alter ego fue simple: las ramas tributarias que pretendían volverse a arrendar habían disminuido y los márgenes de ganancia para el Comercio serían mínimos. Así, firmar un nuevo asiento iba a ser imposible. ${ }^{42}$ Sin embargo, el virrey se apresuró a manifestar que la Corona no buscaba solo un nuevo asiento para obligarlos a saldar las deudas denunciadas por Palata, sino que el fin último de la Corte era alcanzar un acuerdo mediante el cual aumentar las rentas peruanas. Esto animó al Comercio a sentarse con el vicesoberano. Pero, además, la real cédula de 23 de junio de 1688 — que llegó a Lima por esas fechas - facultó a Monclova para componer todos los pleitos que los cargadores tuviesen «sobre las bajas que ha pretendido», ${ }^{43}$ terminándolos por convencer de lo útil, para ambas partes, de convenir un nuevo asiento.

${ }^{41}$ Carta del conde de la Monclova al Rey sobre la supresión de impuestos solicitadas por el Consulado Lima, 20 de junio de 1690. AGI, Lima, 427.

${ }^{42}$ Carta del conde de la Monclova al Rey sobre la primera reunión con el Consulado. Lima, 20 de junio de 1690. AGI, Lima, 427.

${ }^{43}$ Carta del conde de la Monclova al Rey comunicando la aplicación de la real cédula para la composición de los pleitos comerciales. Lima, 20 de junio de 1690. AGI, Lima, 427. 
Así, de una u otra manera, el virrey consiguió que los mercaderes negociaran otro arrendamiento, lo cual demostró que los beneficios obtenidos por esta actividad — la gestión tributaria — seguían siendo importantes. Los representantes del Consulado fueron los primeros en hacer una propuesta: mantendrían los asientos a cambio de 100.000 pesos por armada. Sin embargo, esta primera puja no se acercaba a lo esperado por la Real Hacienda, por lo que el monto se elevó a 150.000, 170.000 y, finalmente, 200.000 pesos. El virrey llevó la oferta final de los mercaderes ante el Real Acuerdo y obtuvo una respuesta positiva para continuar con la confección del asiento. Incluso así, Monclova estimó que en esta negociación salía perdiendo el Erario Regio, pues, tras consultar con los oficiales reales, comprobó que la alcabala rentaba anualmente 160.500 pesos, y el almojarifazgo y la unión de armas, 127.800 pesos los años que había armada y 103.837 pesos los años que no acudían galeones desde la Península. Se trataba de una diferencia considerable, ya que habría años en que, con una gestión directa por parte de la administración virreinal, se recaudarían entre 288.300 y 264.337 pesos de a ocho reales. Por lo tanto, los comerciantes, aceptando el asiento por 200.000 pesos, se embolsarían entre 88.300 y 64.337 pesos anualmente. Así, Monclova cedió y mintió al considerar beneficioso el acuerdo por las cantidades ofertadas por los mercaderes, apoyándose, como ellos, en el repetido descenso de las rentas.

Cuadro 1. Estimación fiscal de 1690 ante la oferta del Consulado

\begin{tabular}{lcc}
\hline Tributo & Año de armada & Año sin armada \\
\hline Alcabala & 160.500 & 160.500 \\
Almojarifazgo y unión de armas & 127.800 & 103.837 \\
Total & 288.300 & 264.337 \\
Beneficio del Consulado & 88.300 & 64.337 \\
\hline
\end{tabular}

Fuente: Carta del conde de la Monclova al Rey sobre las cantidades del asiento con el Consulado. Lima, 20 de junio de 1690. AGI, Lima,

Tras nuevas reuniones, el virrey llegó a un acuerdo definitivo con el Comercio por las siguiente cifras: en concepto de alcabala entregarían 
a la Caja Real de Lima, cuando los galeones fondeasen en Portobello, 160.000 pesos y, cuando no se celebrase aquella feria, 145.000; con el mismo condicionante, las ramas del almojarifazgo y la unión de armas fluctuarían entre 65.000 y 50.000; la avería del Norte y la del Sur, por su parte, no sufrirían modificaciones. Asimismo, como límites temporales se especificó que "corran como han corrido por término de dos armadas que hayan de venir en el de cinco ańos». Además, el Consulado se ofreció a entregar un donativo gracioso de 100.000 pesos de a ocho reales para las necesidades de la Corona, siempre y cuando se le permitiese designar de motu proprio a las personas que ocupasen los diferentes cargos de la administración para el cobro de los citados impuestos. ${ }^{44}$

Sin embargo, lo que pareció un acuerdo cerrado para los intereses virreinales se torció inesperadamente. A pesar de que la actividad pirática había descendido hasta casi desaparecer a finales de la década de 1680 — principalmente por la eficaz persecución realizada por la Compañía de Nuestra Señora de Guía, formada por los propios miembros del Consulado- algunos restos de peligro aún quedaban en actividad. Así fue como en noviembre de 1689 un pequeño grupo de filibusteros asaltaron un navío mercante, prácticamente recién botado desde los astilleros, capturándolo y provocando el pánico entre los cargadores. Estos presionaron a sus representantes para que solicitasen a Monclova la suspensión de las negociaciones asentistas. El virrey, a pesar de la diplomacia demostrada durante su gobierno, se mostró inflexible y expuso ante el Comercio, por medio del prior y los cónsules, que un negocio regio de tal importancia no admitía más retrasos. ${ }^{45}$ La nueva postura del alter ego consiguió el efecto deseado y los comerciantes se atuvieron a volver al estado previo al incidente pirático.

Los cargadores y Monclova continuaron manejando las cifras ya dadas sobre la alcabala, el almojarifazgo, la unión de armas y las dos averías, en 100.000 pesos la del Sur y 350.000 ducados la del Norte, «en cada

${ }^{44}$ Carta del conde de la Monclova al Rey sobre acuerdo alcanzado con el Consulado sobre los asientos. Lima, 20 de junio de 1690. AGI, Lima, 427.

45 Carta del conde de la Monclova al Rey sobre el riesgo de ruptura de las negociaciones con el Consulado por los asientos. Lima, 20 de junio de 1690. AGI, Lima, 427. 
una de las dos armadas que es el término de este asiento». Sin embargo, las posturas surgidas a raíz del ataque pirata hicieron que la suavidad mantenida por ambas partes dejase de existir. El virrey esperaba que su nueva postura — más férrea- se tradujese en el aumento de las cifras favorables a la Real Hacienda, pero los comerciantes se mantuvieron firmes para defender su rentabilidad en estos negocios. Esta situación alargó la consecución del acuerdo definitivo de los asientos durante buena parte de 1690, pues el Comercio amenazaba constantemente al virrey con efectuar el donativo de cancelación de los asientos ofrecido en 1682 — los famosos 100.000 pesos_, invalidando unilateralmente cualquier acuerdo entre ambas partes. Como es de entender, ante esta intimidación, Monclova no tuvo más remedio que enviar los acuerdos a los fiscales de la Audiencia de Lima para conseguir su visto bueno. Obtenida su aprobación, se realizó el ajuste definitivo de los asientos. Así, el 5 de octubre de 1690, se otorgó «el instrumento de asiento» al Tribunal. ${ }^{46}$ Sin lugar a dudas, el poder económico había vuelto a sobrepasar a los intereses de la Corona, doblegándola gracias a su permanente necesidad monetaria y a la ventaja que el factor distancia le otorgaba para gobernar el día a día desde la ciudad de Los Reyes.

\section{Cuadro 2. Asientos virreinato-Consulado firmados el 5 de octubre de 1690}

\begin{tabular}{lcc}
\hline Tributo & Año de armada & Año sin armada \\
\hline Alcabala & 160.000 pesos & 145.000 pesos \\
Almojarifazgo y unión de armas & 65.000 pesos & 50.000 pesos \\
Avería del Mar del Sur & 100.000 pesos & - \\
Avería del Mar del Norte & 87.500 ducados & - \\
\hline
\end{tabular}

Fuente: Carta del conde de la Monclova al Rey sobre la firma del asiento con el Consulado. Lima, 25 de octubre de 1690. AGI, Lima, 427.

Aunque podría pensarse que el lucro del gremio mercantil ya estaba colmado con la consecución de estos nuevos asientos, la realidad demostró lo contrario. Casi a la vez que se firmaban los asientos de 1690, el Comercio 
solicitó ante el Tribunal de Cuentas y la Audiencia limeña una exención del pago de la avería, acogiéndose a la suspensión tributaria dispuesta para incentivar la rápida reconstrucción de Lima y el Callao. Contadores y fiscales negaron esta petición e incluso, sorprendidos, reprendieron a los mercaderes sobre lo inapropiado de la demanda, máxime cuando la actividad comercial estaba volviendo a los ritmos habituales antes del terremoto de 1687. Además, suprimir temporalmente este gravamen «resultaría en perjuicio de los asientos que se habían de celebrar». ${ }^{47}$

Conocidas estas exigencias en la Corte, la respuesta no se hizo esperar, sobre todo porque, para 1692, cuando llegaron las noticias a Madrid, la Monarquía se hallaba inmersa en plena Guerra de los Nueve Años y cualquier leve alteración era tomada como una magnífica excusa para añadir nuevos fondos que alimentasen a los ejércitos españoles. Así, desde el Consejo de Indias se advirtió al Tribunal del Consulado que por su inapropiada petición se iba a realizar una inspección minuciosa a la próxima flota que amarrarse en Cádiz. El terror se apoderó de los cargadores y, para evitar tan gravosa revista, ofrecieron casi de inmediato enterar en la Real Hacienda 2'700.000 escudos de a diez reales de plata. ${ }^{48}$ Estimar la cantidad de mercaderías y metales fraudulentos embarcados en aquella armada resulta más simple si se tiene en cuenta lo pagado para evitar la investigación, pero ese es otro tema que escapa al que estamos tratando.

\section{LA ALCABALA COMO ÚlTimo ASIENTO EN MANOS CONSULARES}

Los comerciantes perdieron al poco tiempo otra batalla contra la Corona en materia fiscal. Si bien por el asiento del 5 de octubre de 1690 quedaron facultados para recaudar el impuesto de la alcabala tal como se venía ejecutando desde la década de 1660, a partir de entonces pasaron a ver cómo sus beneficios en este ramo disminuyeron notablemente. Resultó ser que los hacendados de los valles costeros de la jurisdicción de la Audiencia no dejaron de presionar al Rey para mantener los beneficios

${ }^{47}$ Carta del conde de la Monclova al Rey sobre la petición del Consulado. Lima, 25 de octubre de 1690. AGI, Lima, 427.

${ }^{48}$ Oliva Melgar 1996: 342. 
fiscales obtenidos tras el sismo de 1687. Tan insistentes fueron sus peticiones que, mediante real cédula de 15 de febrero de 1699, Carlos II ordenó a Monclova remitir un memorial sobre la conveniencia de ampliar la exención de la alcabala hecha a los agricultores. Además, desde entonces, la propia Chancillería quedó facultada para decidir si moderar o no los intereses exigidos en los censos contraídos por los terratenientes. ${ }^{49}$ Así, el impuesto transaccional de la alcabala en Lima quedó fijado en solo 4.500 pesos anuales. Quedaba, por tanto, el negocio asentista del Tribunal en una situación delicada, necesitando un nuevo calibrado de los balances de las diferentes ramas de los arrendamientos fiscales.

\section{Cuadro 3. Alcabala del Perú a finales del siglo XVII}

\begin{tabular}{lc}
\hline Caja Real & Pesos de a ocho \\
\hline Lima & 40.000 \\
Cuzco & 20.500 \\
La Paz & 7.000 \\
Oruro & 1.000 \\
Potosí y la Plata & 25.000 \\
Huancavelica y Huamanga & 6.000 \\
Arica & 1.000 \\
Arequipa & 6.000 \\
Chucuito & 2.000 \\
Huánuco & 4.000 \\
Trujillo, Cajamarca, Saña y Chachapoyas & 6.000 \\
Piura & 700 \\
Huarochirí y Canta & 2.500 \\
Chancay, Cajatambo, Huaylas, Jauja, Yauyos, Cañete, Ica y Pisco & 5.000 \\
Quito, Guayaquil, Cuenca, Loja y Jaén & 12.000 \\
\hline Total & 138.700 \\
\hline
\end{tabular}

Fuente: Listado sobre los montos de la renta de la alcabala en el distrito de las Audiencias de Lima, Charcas y Quito. S. 1., ca. 1700. Biblioteca del Palacio Real, mss. 3286. 
El tributo de la alcabala, que solo se había gestionado mediante asiento en la capital del virreinato, era proporcional al volumen de las compra-ventas realizadas. Así, el hecho de que descendiese tanto en Lima, centro de los mayores intercambios del territorio, ${ }^{50}$ no debe explicarse solo por las medidas tomadas tras el terremoto de 1687. Ya se vio, entre otras cosas, que, en la negociación de los asientos, el monto total por este concepto variaba entre los 160.000 y los 145.000 pesos anuales en razón de la presencia de armada o no. Por tanto, debe considerarse que, atendiendo a los datos ofrecidos por la Miscelánea de Ayala para finales del siglo XVII, a la Caja Real de Lima llegaban por la alcabala un total de 138.700 pesos de a ocho reales. ${ }^{51}$ De esta forma, la rebaja impositiva hasta los 4.500 pesos en el distrito limeño no puede explicarse únicamente por medio de la presión de los hacendados a la Corona. Además, el mismo documento comprueba que la economía peruana mantuvo una viveza considerable, pues así lo demuestran las cifras que recoge. Así pues, los cargadores no tuvieron armas con las que negociar de forma agresiva el asiento de este tributo, pues ambas partes conocían la curva — creciente- que estaba trazando la tasa y que beneficiaría, principalmente, a los propios arrendatarios.

\section{A MOdo DE CONCLUSIÓN}

Fue lógico que, en un contexto económico de estancamiento y aumento de precios, la Corona buscase medidas para salir de la delicada situación financiera, pero estas reformas no solo tendieron a la reactivación de las actividades generadoras de riqueza. También, para asegurar el flujo de ingresos en las arcas de las Cajas Reales, se emplearon mecanismos estables como los asientos. No obstante, dado que la autoridad de las estructuras fiscales durante la segunda mitad del siglo XVII se estaba revelando insuficiente y dada la escasa dotación de personal con que esta maquinaria funcionaba, fue prácticamente imposible que los objetivos

\footnotetext{
${ }^{50}$ Escobedo Mansilla 1976.

${ }^{51}$ Listado sobre los montos de la renta de la alcabala en el distrito de las audiencias de Lima, Charcas y Quito. S.l., ca. 1700. Biblioteca del Palacio Real, mss. 3286.
} 
de la Monarquía — crecimiento económico y rentas más o menos fijas - pudieran cumplirse. Por ello, la metrópoli aceptó una práctica perniciosa y conocida para mantener el nivel tributario: la utilización de recaudadores externos a la propia Real Hacienda a cambio de una suma fija anual. Los asientos habían estado reservados para necesidades puntuales en los grandes ramos hacendísticos, pero, a partir de 1664 y 1666, se extendieron por todos los conceptos fiscales del Perú.

La erección en 1613 del Tribunal del Comercio de Lima vino a cubrir en cierta medida esta nueva demanda — entes que pudiesen tomar los asientos con garantías-, pues se trataba de una institución con un marcado carácter económico, vinculada a los mayores productores de rentas y con una estabilidad como pocos organismos "privados» en el Perú. Además, a la Monarquía la unión con el Consulado solo podía resultarle ventajosa, ya que este binomio entablaba unos lazos sólidos entre la Corona y los mayores poseedores de capital en el territorio y, por tanto, aseguraba el acceso inmediato al monto conformado por los diferentes tributos que nutrían al Fisco Regio.

Sin embargo, las buenas perspectivas que se presentaban ante el Consejo de Indias por la entrega de los impuestos a los comerciantes peruanos estuvieron, en buena medida, tergiversadas por un mecanismo que a veces fue obviado: si estos mercaderes no embarcaban sus bienes y capitales en la Armada del Mar del Sur, si no se celebraba feria en Portobello, no existía el instrumento generador de la actividad mercantil, es decir, el sector que tuvo asignadas más tasas fiscales. No obstante, sí se consideró que estas operaciones comerciales iban a producirse invariablemente, por lo que hacer que el Consulado autogestionase la percepción y entrega a la Real Hacienda de los tributos generados por sus componentes se antojó como un buen camino para el aumento de los ingresos hacendísticos.

Además, como el grupo socioeconómico con mayor capacidad para acumular pecunia en todo el virreinato, los comerciantes se presentaban ante la metrópoli como el único "agente social» con el que podían realizarse, con las garantías adecuadas, los asientos impositivos. Este panorama provocó que, al ser la única vía, las condiciones presentadas fuesen cada 
vez más duras. El crecimiento de la tensión entre ambos negociadores también se debió al conocimiento, cada año mayor, de la realidad fiscal que se escondía detrás de cada impuesto, como la dificultad de percepción, la lentitud burocrática, los esquemas rígidos, la variabilidad anual y las exigencias puntuales del Fisco Regio. Así, una vez establecidos los primeros asientos, las renovaciones de estos contratos tributarios no pudieron volverse sino cada vez más dificultosas.

La supresión de la avería en 1660 y la solicitud de su exención por los comerciantes tras el terremoto de 1687 terminaron de configurar un escenario complejo, pues acentuó el rasgo de los mercaderes como los únicos sujetos válidos para hacerse cargo de la necesidad que la Corona presentó en el Perú: el cobro anual de sus propios impuestos. Esta fue la causa que llevó al virrey conde de Santisteban del Puerto (16611666) a tomar como uno de sus principales objetivos la negociación de asientos con el Comercio. Estos acuerdos eran indispensables, pues se había demostrado - y se demostró durante el resto de la centuria- que era el único medio eficaz para asegurar un flujo estable de ingresos a la Real Hacienda, además de favorecer la actividad comercial en un teatro económico en pleno proceso de transformación. Desde este momento y hasta el relevo dinástico, Corona y Consulado no hicieron otra cosa que mostrar deseos contrapuestos - conservar el impuesto en cantidades fijas y enajenables frente a la cancelación de los tributos y la entrega de una compensación-, provocando una inseguridad económica que, a la postre, no sirvió para recuperar el impulso financiero peruano, ni en el ámbito indiano ni en el contexto de la Monarquía católica. Las negociaciones y los asientos no habían restaurado del todo un estado financiero decreciente, pero al menos sí consiguieron dotar de una cierta estabilidad a la Real Hacienda e incentivar, con sus altibajos, a un sector comercial que consiguió — con las dos averías, la alcabala, el almojarifazgo y la unión de armas - aquello que pretendían las propias autoridades metropolitanas: asegurarse unos ingresos anuales. 


\section{BIBLIOGRAFÍA}

Andrien, Kenneth J. 2011. Crisis y decadencia. El Virreinato de Perú en el siglo XVII. Lima: Banco Central de Reserva de Perú e Instituto de Estudios Peruanos.

Caracuel Moyano, Rocío. 1966. «Los mercaderes del Perú y la financiación de los gastos de la Monarquía (1650-1700)». En Jimenez Núnez, Alfredo (ed.). Actas del XXXVI Congreso Internacional de Americanistas. Sevilla: Ecesa, vol. 4, 335-343.

Domínguez Ortiz, Antonio. 1960. Política y Hacienda de Felipe IV. Madrid: Ed. Derecho Financiero.

Escobedo Mansilla, Ronald. 1976. «La alcabala en el Perú bajo los Austrias». Anuario de Estudios Americanos. Vol. XXXIII: 257-307.

García Fuentes, Lutgardo. 1979. «En torno a la reactivación del comercio indianos en tiempos de Carlos II». Anuario de Estudios Americanos. Vol. XXXVI: 251-286.

Hanke, Lewis y Rodríguez, Celso. 1979. Los virreyes españoles en América durante el gobierno de la casa de Austria, Perú. Madrid: Atlas, 7 vols.

Lohmann Villena, Guillermo. 1946. El Conde de Lemos. Virrey de Perú. Madrid: Consejo Superior de Investigaciones Científicas y Escuela de Estudios Hispanoamericanos.

Mendiburu, Manuel de. 1874-1890. Diccionario histórico-biográfico del Perú; primera parte que corresponde a la época de la dominación española. Lima: Imprenta de J. Francisco Solís, 8 vols.

Oliva Melgar, José María. 1996. «Realidad y ficción en el monopolio de las Indias: una reflexión sobre el sistema imperial español en el siglo XVII». Manuscrits. Revista d'història moderna. Núm. 14: 321-355.

Pérez-Mallaína Bueno, Pablo Emilio. 2000. «La fabricación de un mito: el terremoto de 1687 y la ruina de los cultivos de trigo en el Perú». Anuario de Estudios Americanos. Vol. LVII, núm. 1: 69-88. Disponible en: <http:// dx.doi.org/10.3989/aeamer.2000.v57.i1.259>.

Rodríguez Vicente, Encarnación. 1960. El Tribunal del Consulado de Lima en la primera mitad del siglo XVII. Madrid: Ed. Cultura Hispánica.

Serrera Contreras, Ramón María. 1998. «Geografía y poder en el siglo XVII indiano: el factor distancia en el incumplimiento de la norma». En Pinard, Gustavo y Antonio Merchán (eds.). Libro homenaje in memoriam: Carlos Diaz Rementería. Huelva: Universidad de Huelva, 691-699. 
Suárez, Margarita. 1995. Comercio y fraude en el Perú colonial. Las estrategias mercantiles de un banquero. Lima: Banco Central de Reserva del Perú e Instituto de Estudios Peruanos.

. 2001. Desafios transatlánticos. Mercaderes, banqueros y el estado en el Perú virreinal, 1600-1700. Lima: Pontificia Universidad Católica del Perú, Fondo de Cultura Económica e Instituto Francés de Estudios Andinos.

Fecha de recepción: 30/IX/2015

Fecha de aceptación: 8/III/2016 